\title{
Ontology Based Framework to Configure the Organizational Goal Analysis and Decision-Making
}

\author{
Tengku Adil Tengku Izhar \\ Faculty of Information Management, Universiti Teknologi MARA, UiTM Selangor, Malaysia \\ E-mail: tengkuadil@yahoo.co.uk
}

Received: 20 March 2017; Accepted: 27 June 2017; Published: 08 September 2017

\begin{abstract}
Organizational data is essential to assist domain experts and entrepreneurs for decision making process in relation to the organizational goals but the trustworthiness of organizational data in relation to achieving the organizational goals is often questioned because of the vast amount of organizational data available. This paper proposes a methodology to evaluate organizational data that relates to the organizational goals. This refers to the importance of assisting the organization to utilize relevance of organizational data from the vast amount of available data for decision making to the organizational goals. The aim of this paper is to identify dependency relationship of organizational data that match to the organizational goals and to define a metrics as an analysis approach to measure organizational data to be considered relevant to the organizational goals. The experiment is present to implement the propose methodology in the context of Australian economy. The contribution of this paper will serve as a first step in evaluation approach and analysis of organizational data that relates to the achievement of the organizational goals.
\end{abstract}

Index Terms - Organizational data, organizational goals ontology, metrics, dependency relationship.

\section{INTRODUCTION}

Government agencies, public and private bodies are drowning in an ever-increasing deluge of data [1] because they create and collect massive amount of data in their daily business activity. The ability to analyse their data in a timely fashion can provide a competitive edge to improve productivity in relation to the organizational goals. Data is the most important asset to assist the decision making process in achieving the organizational goals. However, the trustworthiness of organizational data in relation to the organizational goals always questionable due to the huge data mining issue within the organization [20]. Some of this data are not relevant to the organizational goals. Therefore, it is difficult to identify the relevance of organizational data even though the professional such as data analysts are trained to analyse this data but the increase amount of organizational data has become a major problem in applying this data in achieving the organizational goals. Modelling the organizational goals structure is important to identify dependency relationship of organizational data that relates to the organizational goals. For example, an ontology improves the understanding of the organizational goals structure as it shows the relationship between the organizational goal elements $[2,3]$.

However, there is shortcoming when it comes to evaluating the organizational data in relation to the organizational goals. Modelling the organization goals limited to the business process and the organizational process [6-9]. The aim of this paper is to present a set of methodology to measure organizational data that relates to the organizational goals as an effort to assist domain experts and entrepreneurs for decision making process in achieving the organizational goals. The contribution of this paper is design to identify dependency relationship of the organizational goals based on ontology [2, 3]. Ontology is important to define a specification of a conceptualization. Ontology is developed to categories some domain within the concept and it is important to improve the understanding of the structure of data or information among people or software. It also enables the use of knowledge within domain and to analyse domain knowledge. In the context of the organizational goals, ontology is developed to improve the understanding of the organization structure and relationship of the organizational goals $[2,3]$.

This paper is present to explain in detail, along with how the proposed model is design, implement and apply to evaluate analysed organizational data that relates to the organizational goals. The purpose of this paper is to validate the flexibility and reliability of the proposed methodology to assist domain experts and entrepreneurs for decision making process in relation to the organizational goals. The experiment evaluation is presented to discover any issues or gaps which may be presented during the implementation of the proposed methodology. This is considered as flexibility to confirm the validity of the proposed methodology that can be applied in any situation. In this paper, the proposed methodology observed the limitation of previous organizational processes in relation to the organizational 
goals $[7,9,10]$. Therefore, model in this methodology defined as an extension approach to introduce the organizational goals process as an effort to measure organizational data that relates to the organizational goals. This paper specify the organizational resource which is organizational data as it is suggested that organizational data is the most important organizational resource in relation to the organizational goals $[2,3]$. The outcome of this paper will improve the process of evaluating organizational data that relates to the organizational goals.

\section{LITERATURE REVIEW}

\section{A. Dependency relationship of organizational goal elements}

The aim of this paper is to propose a methodology to measure organizational data that relates to the organizational goals as an effort to consider this organizational data as relevant data in relation to the organizational goals. In order to achieve this aim, we proposed an ontology as an approach to identify the dependency relationship of the organizational goals element which includes sub-goal and organizational data $[2,3]$. We suggest an ontology is important to improve the understanding of the relationships of the organizational goals elements. Despite the vast amount of research on ontology, there remains relatively little research that applied an ontology for the organizational goals. In this paper, we unified previous models that cater the structure of the organizational goals $[7,9,10]$ Fox et al. [10] addressed an organization to be a set of constraint on the activities performed by the organizations. This study has been extended in Sharma and Osei-Bryson [7], who discussed the relationships such as the business process with a various types of the resources. Sharma and Osei-Bryson [7], and Rao et al. [9] included the entire organization resources in their ontology.

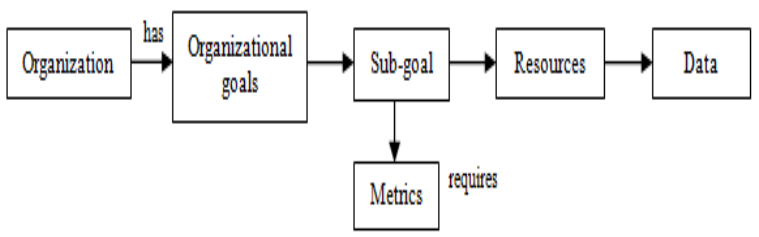

Fig.1. Dependency relationship of organizational goal elements based on ontology.

In contrast to the previous studies, we evaluate the organizational resource which is organizational data. In this paper, we do not interpret the overall business process that includes the overall organizational activities and performance. Instead of evaluating the information and knowledge, we argued that the organizational data is important and must be considered during the decision making process in relation to the organizational goals [2, 3 ] because it is very important to identify the relevance of organizational data in relation to the organizational goals. Most of the previous studies focused on the organizational structure and performance that include the entire business processes and organizational processes [7, $9,10]$. We adapted these studies in the organizational goals ontology as shown in Fig. 1.

Fig. 1 is the extended version of organizational goals ontology $[2,3]$. The figure shows the relationships of the organizational goal elements. It is suggested that it is important to evaluate organizational resource which is organizational data in relation to the organizational goals $[2,3]$ so this organizational data can be considered relevant. It provides domain experts and entrepreneurs with knowledge to identify the most relevance of organizational data in relation to the organizational goals. One approach to evaluate this data is using a metrics as a measurement approach to evaluate the weight of organizational data that relates to the organizational goals [21].

\section{B. Dependency relationship of organizational data to the organization goals}

In this paper, we attempt to identify relevance of organizational data in relation to the organizational goals. Even though there are many studies have been carried out in the context of data process [11, 12], limited studies have been observed in evaluating organizational data in relation to the organizational goals $[2,3]$. Therefore, it is important to identify the relationship of organizational data that relates to the organizational goals. This relationship is important to identify relevance of organizational data from datasets in achieving the organizational goals. However, organizations have a huge set of organizational data that might be relevant to the organizational goals. This large set of organizational data might not be relevant with respect to the organizational goals. Thus, the first step to identify relevance of organizational data is to recognize the matching set of organizational data that relates to the organizational goals.

To achieve this aim, record linkage approach is adapted to identify the possible linkage between organizational data and organizational goals. Record linkage is highly used to identify data that being linked, so all datasets under consideration should ideally undergo a matching process prior to the record linkage [13]. Even though there are studies have been carried out in various issues such as software $[14,15]$, data privacy $[16,17]$ and security [13], we suggest it is important to develop a standard set of approach to show the relationship between data, attributes and organizational goals. Even though the term is defined as record linkage but we use the term data linkage as an effort to identify the relationship between data, attributes and organizational goals because we attempt to identify the linkage for each data and attributes that relates to the organizational goals. We propose data goals linkage based on the organizational goals ontology $[2,3]$ as we define data goals linkage is a task to identify the existing organizational data and attributes from the organizational datasets in relation to the organizational goals as shown in Fig. 2.

\section{Metrics definition to the organizational goals}

In this section, we attempt to measure organizational 
data that relates to the organizational goals. At this stage we identify metrics approach to measure analysed data as an effort for domain experts to come out with decision making process in relation to the organizational goals. Fig. 1 shows the dependency relationship of organizational data and organizational goal. It is important to identify the value for each data and attributes that relates to the organizational goals so this organizational data can be considered as relevance of organizational data in relation to the organizational goals.

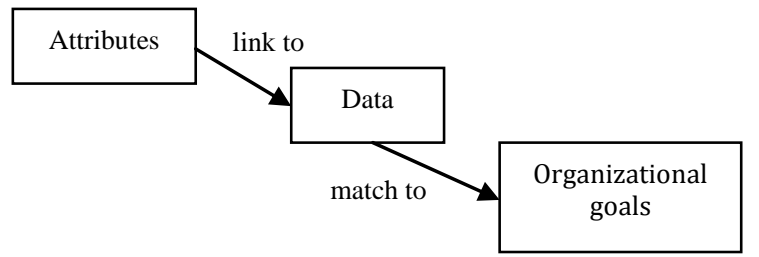

Fig.2. Dependency relationship of organizational data to the organizational goals.

In general, when the value is applied to the number of attribute, the value of weight will change and this value can be define in many ways such as percentage or frequency value. Assuming this value is analysed and it can be presented on the dashboard to show a graphical presentation of value, the comparison of this value can be presented to support decision making process in relation to the organizational goals.

Previous approach in metrics evaluates the weight of the linkage process of matching data [18] for metrics evaluation that used with various types of databases [19]. One approach to measure the value of data is to identify the relationship of data from datasets that match to the organizational goals. Assuming two data, data $a$ and data $b$, from two datasets, dataset $\mathrm{A}$ and dataset $\mathrm{B}$, that represent to the same organizational goals as $a \in A$ and $b \in B_{\text {. }}$

For example, for both data $a$ and $b$ to the same organizational goals, we let

$M=\{(a, b): a \in A, b \in B,(a, b)\}$ is a matching data between data $a$ and $b$ to the same organizational goals,

$U=\{(a, b): a \in A, b \in B,(a, b)\} \quad$ is a nonmatching data between data $a$ and $b$ to the same organizational goals.

However, the aim of the metrics definition is to develop a standard set of measurement approach to assist domain experts or entrepreneurs in decision making process to the organizational goals. Assuming metrics can be used to estimated the number of attribute that match to the sub-goal, the number will be

$$
\begin{gathered}
\text { Sub-goal }=\text { Data } \\
\{\text { attribute } 1+\text { attribute } 2+\text { attribute } 3\}
\end{gathered}
$$

signifying that attribute 1 , attribute 2 and attribute 3 match to sub-goal 1 . The concept of metrics definition in this paper defines the relationship of organizational goals based on the requirement of domain experts and entrepreneurs during decision making process in relation to the organizational goals. Therefore, based on the assumption factor above, the relationship of data and attributes as defined in metrics above will change according to the value of analysed data required by domain experts and entrepreneurs as the assumption for metrics is define as

$$
\text { metrics }=[\mathrm{w}][\mathrm{n}][\mathrm{f}][\mathrm{p}] .
$$

\section{METHODOLOGY}

The aim of the experiments conducted was to evaluate the presented proposed modelling concept within a common business situation. The presented data in this paper were prepared by the Australia Industry Policy and Economic Analysis Branch in the Industry and Small Business Policy Division of the Department of Innovation, Industry, Science and Research. It is available through the small business key facts and statistics link on the department's website at www.innovation.gov.au. The aim of this experiment is to provide a comprehensive overview of Australia's businesses for small, medium and large business size, with emphasis on business counts, characteristics and performance. In order to achieve this aim, the experiment provides information about employment and industry value added by looking at the contribution of business size to Australian economy. Business size is a vital part of the Australian economy, providing almost half of total industry employment and around a third of industry value added in 2009-2010.

In this paper, we applied presented data to evaluate data from industry sector for each business size. The conducted experiment evaluates the proposed methodology to show the dependency relationship of industry sector data and attributes that match to the business size. Therefore, in this experiment, we analysed the contribution of employees and value added by industry sector and business size to provide a comprehensive overview of Australian economy as the overall process of experiment.

\section{A. Test dependencies of data}

Two steps of experiments applied to develop the dependencies of data, the first to identify the existing data and attributes of industry sector, and the second to develop the relationship of this data and attribute that relates to the experiment goal based on an ontology. The aim of this section is to identify the linkage of presented data based on Australia Industry Policy and Economic Analysis by looking at the contribution of the Australia's industry sector to Australia economy. In this experiment, we identified the contribution of employee as sub-goal 1 and contribution of value to Australian economy as subgoal 2. Contribution of employee is the number of employee that contributes to Australian economy for each business size. Contribution of value is the number of industry value added for business size. These two subgoals are the vital part of Australian economy providing almost half of total industry employment and around a 
third of value added in 2009 to 2010 .

\section{B. Evaluation of experiment data}

The aim of this sub-section is to identify the contribution of industry sector to Australian economy by looking at the interaction of number of employee and number of value added in relation to Australian economy. It is important to identify the performance of Australian economy based on the industry sector by observing which sub-goals contribute more to Australian economy. To achieve this aim, the contribution of industry sector for each sub-goal is evaluated in relation to Australian economy. Therefore, the evaluation weight is defines as a metrics to identify the percentage contribution of subgoal 1 and sub-goal 2 to Australian economy. The weight of business size to sub-goals is evaluated based on; 1) higher percentage number of employee, 2) higher number of value added based on the percentage number of employee, 3) business size contribute to sub-goals in relation to Australian economy. It is important to evaluate these categories in order to identify the higher weight percentage of sub-goals that contributes to Australian economy. In the end, it is important to identify which sub-goals have been achieved and contribute more to Australian economy.

In this case study, we defined the linkage of dependency relationship. The weight is evaluated for this dependency relationship of business size to identify the value requirement of sub-goals to be considered achievable to Australian economy. We categories the weight definition based on;

- Goal: Higher contribution to Australian economy.

- Sub-goal_1: Employee contribution to Australian economy.

- Sub-goal_2: Value added contribution to Australian economy.

- Link: Business size

- Business size: Small, medium and large.

The evaluation of percentage weight to Australian economy is shown in Fig. 3 in order to identify which sub-goals contribute more to Australian economy. In this evaluation, weight is also measured based on industry sector for business size that match to Australian economy.

In order to support our explanation, let's take one example from Table 1. Results in Table 1 show the weight of percentage for business size to sub-goal 1 and sub-goal 2. For example, sub-goal 1 show that small business has the highest weight of percentage and this result is supported with the value for each industry sector as shown in Table 4. Weight of small business is evaluated for sub-goal 1 which is number of employee for small business from total number of employee that contributes to Australian economy.

We defined the metrics for sub-goals that contribute to Australian economy as

$$
\text { Goal }=\left(w_{1}[\text { sub-goal 1] })+\left(w_{2}[\text { sub-goal } 2]\right) .\right.
$$

For each sub-goal, we define the metrics as

$$
\begin{aligned}
& \text { Sub-goal } 1=w_{1}[\text { business size }]+w_{2}[\text { employee } \\
& \text { contribution }] / \text { Total number of employee }
\end{aligned}
$$
Sub-goal $2=w_{1}[$ business size $]+w_{2}[$ value added
contribution] $] /$ Total number of value added.

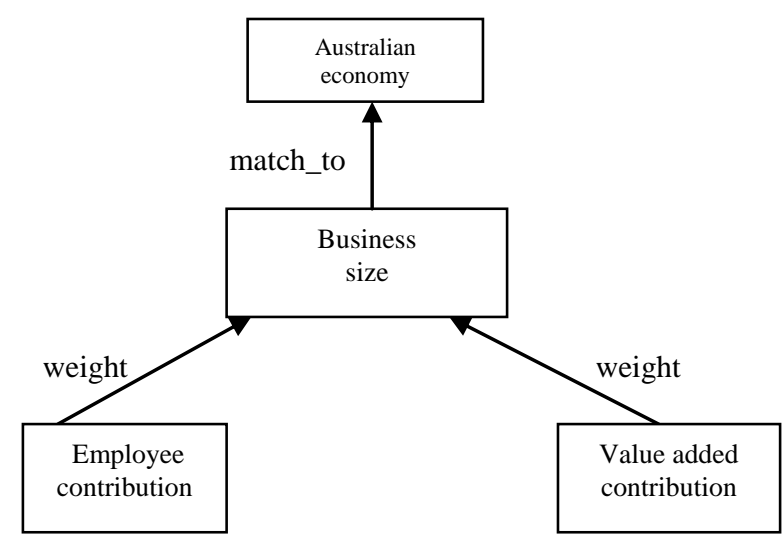

Fig.3. Weight definition to the Australian economy.

\section{Results}

In this experiment, the evaluation is defined to measure the percentage of weight for employee and value added from business size that contributes to Australian economy. Therefore, as discussed earlier, sub-goal 1 is identified as the employee contribution and sub-goal 2 is identified as the value added contribution for each industry sector from business size that contribute to Australian economy.

The aim of this sub-section is to compare which subgoals contribute more to Australian economy. Results in Table 1 show the interaction of weight for business size to sub-goal 1 and sub-goal 2. Table 1 shows a comparison of weight for the overall value for business size that contribute to sub-goals as an effort to assist decision making in relation to Australian economy. In the next stage, the experiment shows the weight for each business size based on industry sector as shown in Table 2, Table 3 and Table 4 in order to support the results in Table 1. The presented weight compares which industry sector for business size contributes more to Australian economy. According to the results, the contribution of business size to Australian economy is somewhat showing a different weight of percentage based on industry sector. Nevertheless, the proposed model identified the value for business size that $r$ to sub-goal 1 and sub-goal 2, therefore the results conclude which subgoals is more achievable to Australian economy. Results in Table 1 shows that large business and small business contribute more to Australian economy compare to medium business with large business doing very well for sub-goal 2 and small business doing very well for subgoal 1. Table 1 conclude that medium business in Australia not doing very well as result show that medium business has the lowest percentage for both sub-goal 1 
and sub-goal 2. To assist our results, Table 2, Table 3 and Table 4 show an interesting knowledge to support the value for each business size in Table 1. Industry sector in these tables match to sub-goal 1 and sub-goal 2 as an effort to supports the weight of business size to Australia economy.

Table 1. Comparison of sub-goals (contribute to Australian economy) based on business size.

\begin{tabular}{|c|c|c|}
\hline \multicolumn{3}{|c|}{$\begin{array}{c}\text { Contribute to } \\
\text { Australian economy }\end{array}$} \\
\hline Business size & $\begin{array}{c}\text { Employee contribution } \\
\text { (Sub-goal1) }\end{array}$ & $\begin{array}{l}\text { Value added } \\
\text { contribution } \\
\text { (Sub-goal 2) }\end{array}$ \\
\hline $\begin{array}{c}\text { Large } \\
\text { business }\end{array}$ & $33.40 \%$ & $48.36 \%$ \\
\hline $\begin{array}{l}\text { Medium } \\
\text { business }\end{array}$ & $23.46 \%$ & $21.87 \%$ \\
\hline $\begin{array}{c}\text { Small } \\
\text { business }\end{array}$ & $43.15 \%$ & $29.77 \%$ \\
\hline Grand Total & $100.00 \%$ & $100.00 \%$ \\
\hline
\end{tabular}

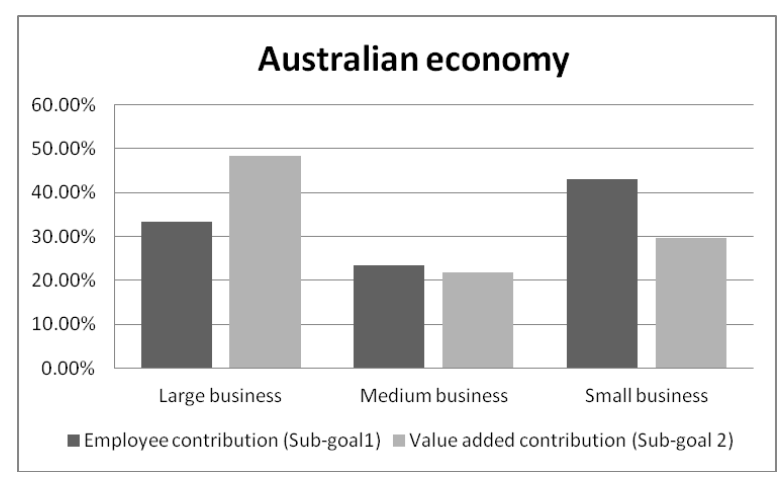

Fig.4. Comparison of sub-goals (contribute to Australian economy) based on business size.

Table 2. Comparison of sub-goals (contribute to Australian economy) based on large business.

\begin{tabular}{|c|c|c|c|}
\hline \multicolumn{4}{|c|}{$\begin{array}{l}\text { Contribute to } \\
\text { Australian economy }\end{array}$} \\
\hline $\begin{array}{l}\text { Busines } \\
\text { s size }\end{array}$ & $\begin{array}{l}\text { Industry } \\
\text { sector }\end{array}$ & $\begin{array}{l}\text { Employee } \\
\text { contribution (Sub- } \\
\text { goal1) }\end{array}$ & $\begin{array}{l}\text { Value added } \\
\text { contribution } \\
\text { (Sub-goal 2) }\end{array}$ \\
\hline \multirow[t]{8}{*}{$\begin{array}{l}\text { Large } \\
\text { business }\end{array}$} & $\begin{array}{l}\text { Agriculture, } \\
\text { forestry and } \\
\text { fishing }\end{array}$ & $0.84 \%$ & $0.25 \%$ \\
\hline & $\begin{array}{l}\text { Education } \\
\text { and training }\end{array}$ & $6.53 \%$ & $2.88 \%$ \\
\hline & $\begin{array}{l}\text { Information } \\
\text { media and } \\
\text { telecommuni } \\
\text { cation }\end{array}$ & $7.44 \%$ & $14.00 \%$ \\
\hline & $\begin{array}{l}\text { Manufacturi } \\
\text { ng }\end{array}$ & $25.54 \%$ & $24.33 \%$ \\
\hline & Mining & $6.95 \%$ & $31.36 \%$ \\
\hline & $\begin{array}{l}\text { Rental, } \\
\text { hiring and } \\
\text { real estate } \\
\text { services } \\
\end{array}$ & $2.11 \%$ & $3.59 \%$ \\
\hline & Retail trade & $39.23 \%$ & $13.49 \%$ \\
\hline & $\begin{array}{l}\text { Wholesale } \\
\text { trade }\end{array}$ & $11.37 \%$ & $10.10 \%$ \\
\hline \multicolumn{2}{|c|}{ Large business Total } & $100.00 \%$ & $100.00 \%$ \\
\hline
\end{tabular}

Table 3. Comparison of sub-goals (contribute to Australian economy) based on medium business.

\begin{tabular}{|c|c|c|c|}
\hline \multicolumn{4}{|c|}{$\begin{array}{l}\text { Contribute to } \\
\text { Australian } \\
\text { economy }\end{array}$} \\
\hline $\begin{array}{l}\text { Business } \\
\text { size }\end{array}$ & Industry sector & $\begin{array}{l}\text { Employee } \\
\text { contribution } \\
\text { (Sub-goal1) } \\
\end{array}$ & $\begin{array}{l}\text { Value added } \\
\text { contribution } \\
(\text { Sub-goal 2) }\end{array}$ \\
\hline \multirow[t]{8}{*}{$\begin{array}{l}\text { Medium } \\
\text { business }\end{array}$} & $\begin{array}{l}\text { Agriculture, } \\
\text { forestry and } \\
\text { fishing }\end{array}$ & $5.49 \%$ & $3.21 \%$ \\
\hline & $\begin{array}{l}\text { Education and } \\
\text { training }\end{array}$ & $13.59 \%$ & $8.40 \%$ \\
\hline & $\begin{array}{l}\text { Information media } \\
\text { and } \\
\text { telecommunication }\end{array}$ & $3.20 \%$ & $3.49 \%$ \\
\hline & Manufacturing & $30.17 \%$ & $30.45 \%$ \\
\hline & Mining & $2.50 \%$ & $16.53 \%$ \\
\hline & $\begin{array}{l}\text { Rental, hiring and } \\
\text { real estate services }\end{array}$ & $4.80 \%$ & $5.83 \%$ \\
\hline & Retail trade & $23.38 \%$ & $13.21 \%$ \\
\hline & Wholesale trade & $16.88 \%$ & $18.87 \%$ \\
\hline \multicolumn{2}{|c|}{ Medium business Total } & $100.00 \%$ & $100.00 \%$ \\
\hline
\end{tabular}

Table 4. Comparison of sub-goals (contribute to Australian economy) based on small business.

\begin{tabular}{|c|c|c|c|}
\hline \multicolumn{4}{|c|}{$\begin{array}{l}\text { Contribute to } \\
\text { Australian } \\
\text { economy }\end{array}$} \\
\hline $\begin{array}{l}\text { Business } \\
\text { size }\end{array}$ & Industry sector & $\begin{array}{l}\text { Employee } \\
\text { contribution } \\
\text { (Sub-goal1) }\end{array}$ & $\begin{array}{l}\text { Value added } \\
\text { contribution } \\
\text { (Sub-goal 2) }\end{array}$ \\
\hline \multirow[t]{8}{*}{$\begin{array}{l}\text { Small } \\
\text { business }\end{array}$} & $\begin{array}{l}\text { Agriculture, } \\
\text { forestry and } \\
\text { fishing }\end{array}$ & $21.73 \%$ & $13.37 \%$ \\
\hline & $\begin{array}{l}\text { Education and } \\
\text { training }\end{array}$ & $5.05 \%$ & $2.29 \%$ \\
\hline & $\begin{array}{l}\text { Information media } \\
\text { and } \\
\text { telecommunication }\end{array}$ & $2.12 \%$ & $2.37 \%$ \\
\hline & Manufacturing & $15.64 \%$ & $14.61 \%$ \\
\hline & Mining & $1.09 \%$ & $6.30 \%$ \\
\hline & $\begin{array}{l}\text { Rental, hiring and } \\
\text { real estate services }\end{array}$ & $15.54 \%$ & $28.98 \%$ \\
\hline & Retail trade & $27.00 \%$ & $18.69 \%$ \\
\hline & Wholesale trade & $11.84 \%$ & $13.39 \%$ \\
\hline \multicolumn{2}{|r|}{ Small business Total } & $100.00 \%$ & $100.00 \%$ \\
\hline
\end{tabular}

Result in Table 2 shows that large business doing well in retail trade that contribute the highest percentage to Australian economy with $39.23 \%$ follow by manufacturing with $25.5 .4 \%$ for sub-goal 1 . However, large business not doing well in agriculture, forestry and fishing with only $0.84 \%$ contribute to Australian economy. Meanwhile, for sub-goal 2, large business doing well in mining that contribute the highest percentage with $31.36 \%$, follow by manufacturing with $24.33 \%$.

In Table 3, results show that medium business doing well in manufacturing that contribute the highest percentage to sub-goal 1 with $30.17 \%$ follow by retail trade with $23.38 \%$. Medium business also doing well in manufacturing to sub-goal 2 with $30.45 \%$ follow by 
wholesale trade with $18.87 \%$. However, it does not doing very well in mining for sub-goal 1 and agriculture, forestry and fishing for sub-goal 2. Meanwhile Table 4 shows that small business doing well in retail trade that contribute $27 \%$ to the sub-goal 1 follow by agriculture, forestry and fishing with $21.73 \%$. For sub-goal 2, small business doing well in rental, hiring and real estate services and retail trade contribute the highest percentage with $28.98 \%$ and $18.69 \%$. However, small business does not doing well in mining for sub-goal 1 with only $1.09 \%$ and education and training for sub-goal 2 with only $2.29 \%$.

In this experiment, evaluation value of analysed data for sub-goal 1 and sub-goal 2 show the interaction value of industry sector in relation to Australian economy. Experiment is applied and we identified the relationship of goals and we identified the linkage between data and goals. This relationship assists the evaluation measurement of analysed data that relates to Australian economy. Based on the experiment result, the result concluded the value of industry sector to sub-goal 1 and sub-goal 2 that contribute to Australian economy.

\section{Evaluation OUtCome From the PROPOSED METHODOLOGY}

The presented experiment assist the implementation process of the proposed methodology considering three main approaches as discussed in the introduction section. Firstly, dependency relationship of organizational goals is presented as the relationship of the experiment sub-goals that relates to the Australian economy. Secondly, dependency relationship of organizational data that relates to the organizational goals is presented as industry sector for business size that match to sub-goal 1 and subgoal 2 in the experiment and finally, definition of metrics as presented to measure the weight of business size that match to sub-goal 1 and sub-goal 2 in relation to Australian economy.

The outcome of this experiment conclude that the proposed methodology in this paper is evaluated based on several steps for domain experts and entrepreneurs to follow for the future implementation as the steps are discussed as following. Data is collected and presented for domain experts and entrepreneurs to assist their decision making in relation to the organizational goals. Firstly, domain experts and entrepreneurs indentify the goals. The process includes the main goals and possible sub-goals that match to the main goals. The collected data should be matched to the goals so that this data can be considered as relevant data to assist decision making process. Early in this paper, we discussed the concept of organizational data and organizational goals. Organizations have a huge set of organizational data that might be relevant to the organizational goals and this organizational data might be not relevant with respect to the organizational goals. Therefore, it is important to recognize the matching set of organizational data that relates to the organizational goals.
1. The proposed methodology can be applied in business environment as presented in the evaluation section. The implementation of the proposed methodology developed the relationship of attributes, sub-goals and goal. The relationship is important as a foundation to identify the relationship for business size that match to subgoals for the achievement of Australian economy.

2. Since the proposed methodology is developed to identify organizational data that relates to the organizational goals so that this data can be considered relevant. The relationship is important to define the metrics as an effort to identify which business size can be considered more achievable to sub-goal 1 and sub-goal 2 for the achievement of Australian economy. This shows the flexibility of the proposed methodology in defining the metrics as a measurement approach as discussed.

3. Unlike other approach of organizational modelling, the proposed methodology provided reliable approach that is flexible and scalable for domain experts and entrepreneurs for decision making in relation to the organizational goals. The proposed methodology presents the reliability of the model to identify the dependency relationship of organizational data that relates to the organizational goals.

Assuming that data is collected and goals are defined, domain experts and entrepreneurs define a metrics as a measurement process to analyse this data in relation to the organizational goals. When analysed data is presented the value of weight will change and this value can be defined in many ways such as percentage as discussed in the experiment section. Meanwhile, assuming this value is analysed and presented as a graphical presentation, the comparison of this value is presented to support decision making process in relation to the organizational goals. Domain experts and entrepreneurs can decide which goals have been achieved more and which goals have been achieved less.

The proposed model will serve as an approach steps in understanding the evaluation approach to analyse organizational data that can assist in the achievement of the organizational goals.

\section{CONCLUSION}

We have presented the design, implementation and evaluation of the proposed methodology for the achievement of the organizational goals. The purpose of the proposed methodology is to evaluate organizational data that relates to the organizational goals as this organizational data is consider relevant in relation to the organizational goals. In the first half of this paper, we discussed the concept of proposed methodology with three main approaches. The approaches included identifying the organizational goal elements, identifying the relationship of organizational data that relates to the organizational goals and to define the metrics 
measurement as an effort to evaluate organizational data as relevance of organizational data in relation to the organizational goals. In the second half of this paper, we implemented the experimental approach to the proposed model. We applied data from Australia Industry Policy and Economic Analysis Branch in the Industry and Small Business Policy Division of the Department of Innovation, Industry, Science and Research. The presented data showed the contribution of employees and value added based on Australian industry sector for business size to the Australian economy. Results show the interaction value of industry sector that match to subgoal 1 and sub-goal 2 in relation to Australian economy.

\section{REFERENCES}

[1] P. Christen, "A survey of indexing techniques for scalable record linkage and deduplication," IEEE Transaction on Knowledge and Data Engineering, vol. 24, pp. 1537-1555, 2012.

[2] T. A. T. Izhar, T. Torabi, I. Bhatti, and F. Liu, "Analytical dependency between organisational goals and actions: Modelling concept," in International Conference on Innovation and Information Management (ICIIM 2012) Chengdu, China, 2012.

[3] T. A. T. Izhar, T. Torabi, M. I. Bhatti, and F. Liu, "Recent developments in the organization goals conformance using ontology," Expert Systems with Applications, vol. 40, pp. 4252-4267, 2013.

[4] O. Romero and A. Abello, "A framework for multidimensional design of data warehouses from ontologies," Data \& Knowledge Engineering, vol. 69, pp. 1138-1157, 2010.

[5] A. Mikroyannidis and B. Theodoulidis, "Ontology management and evolution for businee intelligence," International Journal of Information Management, vol. 30, pp. 559-566, 2010.

[6] M. S. Fox, M. Barbuceanu, and M. Gruninger, "An organisation ontology for enterprise modeling: Preliminary concepts for linking structure and behaviour," Computers in Industry, vol. 29, pp. 123-134, 1996.

[7] S. Sharma and K.-M. Osei-Bryson, "Organizationontology based framework for implementing the business understanding phase of data mining projects," in International Conference on System Sciences, Hawaii, 2008, p. 27.

[8] G. Mansingh, K.-M. Osei-Bryson, and H. Reichgelt, "Building ontology-based knowledge maps to assist knowledge process outsourcing decisions," Knowledge Management Research and Practice, vol. 7, pp. 37-51, 2009.

[9] L. Rao, G. Mansingh, and K.-M. Osei-Bryson, "Building ontology based knowledge maps to assist business process re-engineering," Decision Support Systems, vol. 52, pp. 577-589, 2012.

[10] M. S. Fox, M. Barbuceanu, M. Gruninger, and J. Lin, "An organization ontology for enterprise modelling," in Simulation organizations: Computational models of institutions and groupsAAAI/MIT Press, ed, 1998, pp. 131152.

[11] S.-H. Liao, W.-J. Chang, and C.-C. Lee, "Mining marketing maps for business alliances," Expert Systems with Applications, vol. 35, pp. 1338-1350, 2008.

[12] H.-C. Kum, D. F. Duncan, and C. J. Stewart, "Supporting self-evaluation in local government via Knowledge Discovery and Data Mining," Government Information
Quarterly, vol. 26, pp. 295-304, 2009

[13] E. Durham, Y. Xue, M. Kantarcioglu, and B. Malin, "Quantifying the correctness, computational complexity, and security of privacy-preserving string comparators for record linkage," Information Fusion, vol. 13, pp. 245-259, 2012.

[14] S. M. Freire, R. T. d. Almeida, M. D. B. Cabral, E. d. A. Bastos, R. C. Souza, and M. G. P. d. Silva, "A record linkage process of a cervical cancer screening database," Computer Method and Program in Biomedecine, vol. 108, pp. 90-101, 2012.

[15] D. P. Jutte, L. L. Roos, and M. D. Brownell, "Administrative record linkage as a tool for public health research," Annual Review Public Health vol. 32, pp. 91108, 2011

[16] D. Abril, G. Navarro-Arribas, and V. Torra, "Improving record linkage with supervised learning for disclosure risk assessment," Information Fusion, vol. 13, pp. 274-284, 2012.

[17] A. Karakasidis and V. S. Verykios, "Secure blocking+secure matching $=$ secure record linkage," Journal of Computing Science and Engineering, vol. 5, pp. 223-235, 2011.

[18] C. E. Varghese and G. N. Sundar, "Record matching: Improving performance in classification," International Journal on Computer Science and Engineering, vol. 3, pp. 1207-1212, 2011

[19] T. N. Herzog, F. J. Sheuren, and W. E. Winkler, Data quality and record linkage technique. Washington, USA: Spinger, 2007.

[20] B. Nugraha, I. Ekasurya, G. Osman and M. Alaydrus, " Analysing of porwer consumtion efficiency on various IoT and Cloud-based wireless health monitoring systems: A survey," International Journal of Information Technology and Computer Science, vol.9, pp. 31-39, 2017.

[21] H.J.Bhatti and B.B. Rad," Databases in cloud computing: A literature review," International Journal of Information Technology and Computer Science, vol.9, pp. 9-17, 2017.

\section{Authors' Profiles}

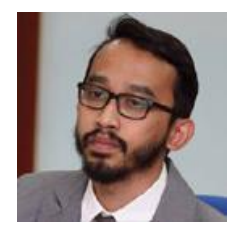

Dr. Tengku Adil is a Senior lecturer at the Faculty of Information Management, Universiti Teknologi MARA, Malaysia. His research interest includes information management, big data, ontology and social media.

How to cite this paper: Tengku Adil Tengku Izhar, "Ontology Based Framework to Configure the Organizational Goal Analysis and Decision-Making", International Journal of Information Technology and Computer Science(IJITCS), Vol.9, No.9, pp. 53-59, 2017. DOI: 10.5815/ijitcs.2017.09.05 